\title{
Sistem Pendukung Keputusan Menentukan Aparatur Sipil Negara Terbaik Pada Dinas Pengelolaan Sumber Daya Air Unit Pelaksana Teknis Dinas dengan Metode Simple Additive Weighting
}

\author{
Sumarno $^{1}$, Indra Gunawan ${ }^{1}$, Heru Satria Tambunan ${ }^{2}$ \\ ${ }^{1}$ Teknik Informatika, STIKOM Tunas Bangsa, Pematangsiantar, Indonesia \\ ${ }^{2}$ Sistem Informasi, STIKOM Tunas Bangsa, Pematangsiantar, Indonesia \\ Email: ${ }^{1}$ sumarno@amiktunasbangsa.ac.id, ${ }^{2}$ indra@amiktunasbangsa.ac.id, ${ }^{3}$ heru@amiktunasbangsa.ac.id
}

\begin{abstract}
Abstrak- Dinas Pengelolaan Sumber Daya Air mempunyai tugas pokok menyelenggarakan sebagian urusan pemerintahan kabupaten di bidang pengelolaan sumber daya air berdasarkan asas otonomi yang menjadi kewenangan, tugas dekonsentrasi dan pembantuan serta tugas lain sesuai dengan kebijakan yang ditetapkan oleh Bupati berdasarkan peraturan perundangundangan yang berlaku. Penilaian kinerja yang dilakukan di instansi ini ditujukan untuk Aparatur Sipil Negara. proses penilaian dilakukan untuk pengukuran dan perbaikan kinerja Aparatur Sipil Negara sehingga dapat mendorong pegawaipegawai tersebut untuk bekerja lebih baik lagi. Dari hasil penilaian atasan dapat ditentukan pegawai terbaik atau promosi jabatan. Proses penilaian kinerja yang dilakukan oleh dinas kebudayaan dan pariwisata masih dilakukan secara manual, sehingga perhitungan kinerja cenderung subyektif dan membutuhkan waktu yang tergolong lama. Oleh karena itu agar proses penilaian kinerja pegawai menjadi lebih obyektif dan praktis, sebaiknya dilakukan secara komputerisasi dengan mengembangkan suatu aplikasi yang mengimplementasikan metode-metode yang tepat. Subjektifitas ini dapat diatasi dengan sistem pendukung keputusan menggunakan metode Simple Additive Weighting(SAW) berdasarkan kriteria-kriteria penilaian yang ada. Hasil akhir penelitian adalah ranking nilai pegawai yang dapat menjadi pertimbangan bagi pengambil keputusan dalam penentuan promosi jabatan sekaligus menjadi penyemangat bagi karyawan untuk bekerja lebih baik dan produktif.
\end{abstract}

Kata Kunci: Penilaian Kinerja, Sistem Pendukung Keputusan, Simple Additive Weighting (SAW)

\begin{abstract}
Abstrack-The Water Resources Management Agency has the main duty to organize some district government affairs in the field of water resources management based on the principle of autonomy which becomes the authority, deconcentration and assistance duty and other tasks in accordance with the policy stipulated by the Regent based on the applicable laws and regulations. The performance appraisal undertaken in this agency is intended for the Civil State Apparatus. the assessment process is carried out for measuring and improving the performance of the State Civil Apparatus so as to encourage these employees to work better. From the assessment of the superior can be determined the best employee or promotion position. The performance appraisal process conducted by the culture and tourism office is still done manually, so the performance calculation tends to be subjective and takes a long time. Therefore, in order that the process of appraising employee performance becomes more objective and practical, it should be done computerized by developing an application that implements the right methods. This subjectivity can be overcome with decision support system using Simple Additive Weighting (SAW) method based on existing assessment criteria. The end result of research is the rank of employee value that can be a consideration for decision makers in the determination of promotions as well as an encouragement for employees to work better and productive.
\end{abstract}

Keywords: Performance Appraisal, Decision Support System, Simple Additive Weighting (SAW)

\section{PENDAHULUAN}

Aparatur Sipil Negara yang selanjutnya disingkat ASN adalah profesi bagi pegawai negeri sipil dan pegawai pemerintah dengan perjanjian kerja yang bekerja pada instansi pemerintah. Pegawai Aparatur Sipil Negara yang selanjutnya disebut Pegawai ASN adalah pegawai negeri sipil dan pegawai pemerintah dengan perjanjian kerja yang diangkat oleh pejabat pembina kepegawaian dan diserahi tugas dalam suatu jabatan pemerintahan atau diserahi tugas negara lainnya dan digaji berdasarkan peraturan perundang-undangan. Pegawai Negeri Sipil yang selanjutnya disingkat PNS adalah warga negara Indonesia yang memenuhi syarat tertentu, diangkat sebagai Pegawai ASN secara tetap oleh pejabat pembina kepegawaian untuk menduduki jabatan pemerintahan. (UndangUndang Nomor 5 Tahun 2014 tentang Aparatur Sipil Negara)

Sumber Daya Manusia (SDM) merupakan salah satu faktor yang sangat penting dari jalannya suatu organisasi atau perusahaan. Pengelolaan yang baik dari pegawai ini akan sangat mempengaruhi aspek keberhasilan kerja. Jika pegawai dapat diorganisir dengan baik, diharapkan organisasi atau perusahaan dapat menjalankan semua proses usaha dengan baik pula. Penilaian kinerja merupakan cara untuk mengetahui kemampuan dari setiap pegawai di suatu perusahaan maupun instansi, penilaian kinerja dilakukan untuk mendapatkan data-data yang valid mengenai kompentensi pegawai sebagai bahan pertimbangan bagi atasan dalam pengembangan karir dan pemberian reward kepada pegawai tersebut.

Masalah subyektifitas dalam penilaian kinerja pegawai merupakan hal yang hampir tidak bisa dihindari. Penilaian secara kuantitatif sering dianggap mengecewakan karena sulitnya mengukur parameter-parameter yang ada. Di lain pihak manajemen dan pegawai membutuhkan proses penilaian kinerja yang rutin dan cepat sehingga dapat memberikan umpan balik dan perbaikan yang cepat di lingkungan kerja. 
Upaya penentuan secara objektif kenaikan jabatan pegawai ini akan sangat bermanfaat untuk memotivasi pegawai supaya dapat bekerja dengan baik. Upaya untuk penentuan kenaikan jabatan pegawai ini terdiri dari sejumlah kriteria yang perlu untuk dipertimbangkan dengan adanya sejumlah alternatif pegawai. Untuk penyelesaian permasalahan ini dapat dilakukan dengan merancang suatu aplikasi yang menggunakan metode Simple Additive Weighting (SAW). Pengisian bobot kriteria akan dilakukan oleh pihak atasan pegawai. Sedangkan pengisian bobot tiap alternatif untuk masing-masing kriteria dapat dilakukan oleh Ka. UPTD 07 Tanah Jawa.

Masalah evaluasi kerja, perencanaan karir atau promosi jabatan dalam pegawai negeri penting dilakukan karena berkaitan dengan prestasi yang dicapai oleh setiap pegawai. Dengan melakukan proses penilaian, maka prestasi yang dicapai setiap pegawai dengan nilai baik sekali, baik, cukup, atau kurang bisa diketahui.

Proses evaluasi kinerja pegawai untuk promosi jabatan, khususnya dalam proses pengelolaan data penilaian Dinas Pengelolaan Sumber Daya Air (PSDA) Unit Pelaksana Teknis Dinas (UPTD) 07 Tanah Jawa Kabupaten Simalungun merupakan penilaian yang kurang akurat dikarenakan penumpukan dokumen dan berkas penilaian kinerja pegawai didalam arsip yang tidak terstruktur. Bagian Personalia atau HRD (Human Resource Departement) harus mengecek ulang dan mengumpulkan data-data pegawai sesuai dengan kriteria yang dibutuhkan. Sehingga, proses pengambilan keputusan mengenai promosi jabatan membutuhkan waktu yang cukup lama.

Proses penilaian yang lengkap harus menunggu dalam jangka waktu yang tak tentu dikarenakan data penilaian yang selalu berpindah tangan antara pihak kepala seksi dan kepala bagian terkait, serta kepala cabang. Penilaian masih berdasarkan ingatan, hal ini menyebabkan pihak penilai terkait merasa kesulitan ketika melihat data pegawai yang dominan dalam kinerjanya. Sehingga, terkadang ada pegawai yang mendapatkan promosi jabatan hanya melihat pada kriteria pertama saja, tetapi pegawai tersebut belum tentu unggul pada beberapa kriteria-kriteria lain. Namun, terkadang ada juga pegawai yang tidak lulus pada kriteria pertama, tetapi Ia dilihat dari kelebihan-kelebihan pada kriteria-kriteria selanjutnya. Serangkaian kriteria yang berurutan tersebut bertujuan untuk mengurangi subjektifitas proses pengambilan keputusan akibat banyaknya alternatif.

Untuk itu agar dapat meningkatkan kualitas kinerja pegawai negeri khususnya pegawai yang baik dan dapat menunjang kemajuan negara khususnya di Dinas Pengelolaan Sumber Daya Air (PSDA) Unit Pelaksana Teknis Dinas (UPTD) 07 Tanah Jawa Kabupaten Simalungun, maka dipandang perlu dilakukannya perbaikan sebuah sistem atau pengelolaanya dengan baik dan terarah, agar dapat mengevaluasi kinerja-kinerja pegawai yang dapat dipromosikan pada jabatan-jabatan tertentu khususnya untuk Unit Pelaksana Teknis Dinas (UPTD) 07 Tanah Jawa Kabupaten Simalungun.

\section{METODE PENELITIAN}

\subsection{Sistem Pendukung Keputusan (SPK)}

Konsep-konsep mengenai sistem pendukung keputusan atau Decision Support System diungkapkan pertama kali oleh Scott Morton pada awal 1970 dengan istilah "Management Decision System". Management Decision System merupakan suatu sistem berbasis komputer yang membantu mengambil keputusan dengan memanfaatkan data dan model untuk menyelesaikan masalah yang tidak terstruktur. (Turban, 2005).

\subsection{Algoritma}

Algoritma merupakan langkah-langkah penyelesaian masalah dalam bentuk kalimat dengan jumlah kata terbatas tetapi tersusun secara logis dan sistematis. Algoritma juga merupakan suatu prosedur yang jelas untuk menyelesaikan suatu persoalan dengan menggunakan langkah-langkah tertentu dan terbatas jumlahnya. Ciriciri Algoritma ini saya berpandangan sesuai dengan pendapat seorang ahli dibidang teknologi dan sains yaitu Donald E. Knuth yang menyatakan bahwa ada beberapa ciri algoritma, yaitu:

1. Algoritma mempunyai awal dan akhir, suatu algoritma harus berhenti setelah mengerjakan serangkaian tugas. Dengan kata lain, suatu algoritma memiliki langkah yang terbatas.

2. Setiap langkah harus didefinisikan dengan tepat sehingga tidak memiliki arti ganda, tidak membingungkan (not ambigous).

3. Memiliki masukan (input) atau kondisi awal.

4. Memiliki keluaran (output) atau kondisi akhir.

5. Algoritma harus efektif, bila diikuti benar-benar maka akan menyelesaikan persoalan.

\subsection{Fuzzy Multiple Attribute Decision Making Methods (FMADMM)}

Fuzzy Multiple Attribute Decision Making Methods adalah sekumpulan algoritma pemilihan untuk menentukan sebuah keputusan, algoritma SAW merupakan sub bagian pada kesatuan ini.

\subsubsection{Metode Algoritma Simple Additive Weighting (SAW)}

Algoritma SAW sering juga dikenal dengan istilah algoritma penjumlahan terbobot. Konsep dasar algoritma SAW adalah mencari penjumlahan terbobot dari rating kinerja pada setiap alternatif pada semua atribut. 
Algoritma SAW membutuhkan proses normalisasi matriks keputusan ke suatu skala yang dapat dibandingkan dengan semua rating alternatif yang ada.

Terdapat beberapa langkah dalam menggunakan algoritma SAW untuk memecahkan masalah, langkah-langkah perhitungan dengan algoritma SAW adalah sebagai berikut :

1. Mendefinisikan masalah dan menentukan tujuan, kriteria, dan alternatif yang dibutuhkan.

2. Memberikan nilai bobot $(\mathrm{Wj})$ pada tiap kriteria $(\mathrm{Cj})$.

3. Memberikan nilai setiap alternatif (Ai) pada setiap kriteria $(\mathrm{Cj})$ yang sudah ditentukan, dimana nilai $\mathrm{i}=$ $1,2,3, \ldots, \mathrm{m}$, dan $\mathrm{j}=1,2,3, \ldots, \mathrm{n}$.

4. Melakukan normalisasi matriks dengan cara menghitung nilai rating kinerja ternormalisasi (rij) dari alternatif (Ai) pada atribut $(\mathrm{Cj})$ berdasarkan persamaan yang disesuaikan dengan jenis atribut (atribut keuntungan ataupun biaya).

Jika j adalah atribut keuntungan (benefit) :

$r_{i j}=\frac{x_{i j}}{\max x_{i j}}$

Jika j adalah atribut biaya (cost) :

$r_{i j}=\frac{\min x_{i j}}{x_{i j}}$

Keterangan :

$\begin{array}{ll}\mathrm{r}_{\mathrm{ij}} & \text { : nilai rating kinerja ternormalisasi } \\ \mathrm{x}_{\mathrm{ij}} & \text { : nilai atribut yang dimiliki dari setiap kriteria } \\ \max _{\mathrm{ij}} & \text { : nilai terbesar dari setiap kriteria } \\ \min _{\mathrm{ij}} & \text { : nilai terkecil dari setiap kriteria } \\ \text { Benefit } & \text { : jika nilai terbesar adalah terbaik } \\ \operatorname{cost} & \text { : jika nilai terkecil adalah terbaik }\end{array}$

5. Hasil akhir diperoleh dari proses perangkingan, yaitu hasil penjumlahan dari perkalian matriks ternormalisasi $\left(\mathrm{r}_{\mathrm{ij}}\right)$ dengan nilai bobot $(\mathrm{Wj})$ sehingga diperoleh semua nilai untuk setiap alternatif (Ai), dan nilai alternatif terbesar adalah yang dipilih sebagai alternatif terbaik dan digunakan sebagai solusi. Untuk mengetahui nilai dan rangking setiap alternatif (Vi) adalah dengan cara sebagai berikut:

$$
\mathrm{Vi}=\sum_{j=1}^{n} W_{j} r_{i j}
$$

Keterangan :

$\mathrm{Vi} \quad$ : nilai untuk setiap alternatif

Wj : nilai bobot dari setiap kriteria

$\mathrm{r}_{\mathrm{ij}} \quad$ : nilai rating kinerja ternormalisasi

\section{ANALISA DAN PEMBAHASAN}

Dalam menyelesaikan kasus pada penelitian ini, yaitu: Merekomendasikan pegawai yang terbaik, berikut di bawah ini didapat kriteria-kriteria yang digunakan untuk melakukan penilaian pegawai.

Kriteria:

$$
\begin{aligned}
& \mathrm{K} 1=\text { Kesetiaan } \\
& \mathrm{K} 2=\text { Prestasi Kerja } \\
& \mathrm{K} 3=\text { Tanggung jawab } \\
& \mathrm{K} 4=\text { Ketaatan }
\end{aligned}
$$

$$
\begin{aligned}
& \text { K5 }=\text { Kejujuran } \\
& \text { K6 }=\text { Kerjasama } \\
& \text { K7 }=\text { Prakarsa }
\end{aligned}
$$

Untuk menyelesaikan pengambilan keputusan berdasarkan perhitungan algoritma Simple Additive Weighting $(S A W)$, hal pertama yang dilakukan adalah Menentukan nilai kriteria $\mathrm{Cj}$ pada suatu set alternatif Ai. Beserta bobot preferensi $(\mathrm{Wj})$ setiap kriteria $\mathrm{Cj}$, berikut kriteria-kriteria yang dibutuhkan dalam pengambilan keputusan merekomendasikan pegawai terbaik dapat dilihat pada tabel 1 berikut:

Tabel 1. Kriteria

\begin{tabular}{lll}
\hline Kriteria & Keterangan & Bobot \\
\hline K1 & Kesetiaan & $20 \%=0,20$ \\
K2 & Prestasi Kerja & $15 \%=0,15$ \\
K3 & Tanggung Jawab & $15 \%=0,15$ \\
\hline
\end{tabular}




\begin{tabular}{lll} 
K4 & Ketaatan & $10 \%=0,10$ \\
K5 & Kejujuran & $15 \%=0,15$ \\
K6 & Kerjasama & $10 \%=0,10$ \\
K7 & Prakarsa & $15 \%=0,15$ \\
\hline
\end{tabular}

Standart nilai algoritma SAW dapat dilihat pada tabel 2 berikut:

Tabel 2. Standart Nilai Algoritma SAW

\begin{tabular}{lll}
\hline Nilai & Parameter Nilai & Keterangan \\
\hline 1 & $0-20$ & Sangat Rendah \\
2 & $21-40$ & Rendah \\
3 & $41-60$ & Cukup \\
4 & $61-80$ & Tinggi \\
5 & $81-100$ & Sangat Tinggi \\
\hline
\end{tabular}

Berikut adalah tabel data pegawai di Dinas Pengelolaan Sumber Daya Air (PSDA) Unit Pelaksana Teknis Dinas (UPTD) 07 Tanah Jawa Kabupaten Simalungun yang telah terdata dapat dilihat pada tabel 3 berikut:

Tabel 3. Hasil Seleksi Data Pegawai pada Algoritma SAW

\begin{tabular}{cllccccccc}
\hline Alternatif & Nip & Nama & $(\mathrm{K} 1)$ & $(\mathrm{K} 2)$ & $(\mathrm{K} 3)$ & $(\mathrm{K} 4)$ & $(\mathrm{K} 5)$ & $(\mathrm{K} 6)$ & $(\mathrm{K} 7)$ \\
\hline P1 & 198404042010011009 & Rizal & 91 & 77 & 78 & 77 & 78 & 77 & 78 \\
P2 & 196912222007011006 & Abon Siringo-ringo & 89 & 78 & 77 & 60 & 77 & 78 & 40 \\
P3 & 196707162007011007 & Musliman & 80 & 60 & 60 & 80 & 81 & 60 & 60 \\
P4 & 197401172007011004 & Misnan & 80 & 60 & 77 & 81 & 40 & 60 & 60 \\
P5 & 19661112008011001 & Edy Muliono & 80 & 60 & 40 & 80 & 81 & 81 & 75 \\
\hline
\end{tabular}

Berikut adalah tabel nilai setelah dikonversi berdasarkan alternatif dan kriteria yang telah terdata. Hasil konversi dapat dilihat pada tabel 4 berikut:

Tabel 4. Nilai Setelah Dikonversi pada Algoritma SAW

\begin{tabular}{cllccccccc}
\hline Alternatif & Nip & Nama & (K1) & (K2) & (K3) & (K4) & (K5) & (K6) & (K7) \\
\hline P1 & 19840404 201001 1 1009 & Rizal & 5 & 4 & 4 & 4 & 4 & 4 & 4 \\
P2 & 196912222007011006 & Abon Siringo-ringo & 5 & 4 & 4 & 3 & 4 & 4 & 2 \\
P3 & 196707162007011007 & Musliman & 4 & 3 & 3 & 4 & 5 & 3 & 3 \\
P4 & 197401172007011004 & Misnan & 4 & 3 & 4 & 5 & 2 & 3 & 3 \\
P5 & 19661112008011001 & Edy Muliono & 4 & 3 & 2 & 4 & 5 & 5 & 4 \\
\hline
\end{tabular}

Setelah bobot alternatif telah disesuaikan dengan nilai kecocokan maka masuk ketahap normalisasi sebagai berikut:

$$
\mathrm{r}_{\mathrm{ij}}=\frac{x i j}{\max x i j} ; \quad \text { dimana jika } \mathrm{j} \text { adalah atribut keuntungan (benefit) }
$$

Untuk normalisasi 1 :

$$
\begin{aligned}
& \mathrm{R} 11=\frac{5}{\max (5 ; 5 ; 4 ; 4 ; 4)}=\frac{5}{5}=1 \\
& \mathrm{R} 12=\frac{5}{\max (5 ; 5 ; 4 ; 4 ; 4)}=\frac{5}{5}=1 \\
& \mathrm{R} 13=\frac{4}{\max (5 ; 5 ; 4 ; 4 ; 4)}=\frac{4}{5}=0,8 \\
& \mathrm{R} 14=\frac{4}{\max (5 ; 5 ; 4 ; 4 ; 4)}=\frac{4}{5}=0,8 \\
& \mathrm{R} 15=\frac{4}{\max (5 ; 5 ; 4 ; 4 ; 4)}=\frac{4}{5}=0,8
\end{aligned}
$$

Untuk normalisasi 2 :

$$
\begin{aligned}
& \mathrm{R} 21=\frac{4}{\max (4 ; 4 ; 3 ; 3 ; 3)}=\frac{4}{4}=1 \\
& \mathrm{R} 22=\frac{4}{\max (4 ; 4 ; 3 ; 3 ; 3)}=\frac{4}{4}=1 \\
& \mathrm{R} 23=\frac{3}{\max (4 ; 4 ; 3 ; 3 ; 3)}=\frac{3}{4}=0,75 \\
& \mathrm{R} 24=\frac{3}{\max (4 ; 4 ; 3 ; 3 ; 3)}=\frac{3}{4}=0,75 \\
& \mathrm{R} 25=\frac{3}{\max (4 ; 4 ; 3 ; 3 ; 3)}=\frac{3}{4}=0,75
\end{aligned}
$$

Untuk normalisasi 3:

$$
\mathrm{R} 31=\frac{4}{\max (4 ; 4 ; 3 ; 4 ; 2)}=\frac{4}{4}=1
$$




$$
\begin{aligned}
& \mathrm{R} 32=\frac{4}{\max (4 ; 4 ; 3 ; 4 ; 2)}=\frac{4}{4}=1 \\
& \mathrm{R} 33=\frac{3}{\max (4 ; 4 ; 3 ; 4 ; 2)}=\frac{3}{4}=0,75 \\
& \mathrm{R} 34=\frac{4}{\max (4 ; 4 ; 3 ; 4 ; 2)}=\frac{4}{4}=1 \\
& \mathrm{R} 35=\frac{2}{\max (4 ; 4 ; 3 ; 4 ; 2)}=\frac{2}{4}=0,5
\end{aligned}
$$

Untuk normalisasi 4:

$$
\begin{aligned}
& \mathrm{R} 41=\frac{4}{\max (4 ; 3 ; 4 ; 5 ; 4)}=\frac{4}{5}=0,8 \\
& \mathrm{R} 42=\frac{3}{\max (4 ; 3 ; 4 ; 5 ; 4)}=\frac{3}{5}=0,6 \\
& \mathrm{R} 43=\frac{4}{\max (4 ; 3 ; 4 ; 5 ; 4)}=\frac{4}{5}=0,8 \\
& \mathrm{R} 44=\frac{5}{\max (4 ; 3 ; 4 ; 5 ; 4)}=\frac{5}{5}=1 \\
& \mathrm{R} 45=\frac{4}{\max (4 ; 3 ; 4 ; 5 ; 4)}=\frac{4}{5}=0,8
\end{aligned}
$$

Untuk normalisasi 5:

$$
\begin{aligned}
& \mathrm{R} 51=\frac{4}{\max (4 ; 4 ; 5 ; 2 ; 5)}=\frac{4}{5}=0,8 \\
& \mathrm{R} 52=\frac{4}{\max (4 ; 4 ; 5 ; 2 ; 5)}=\frac{4}{5}=0,8 \\
& \mathrm{R} 53=\frac{5}{\max (4 ; 4 ; 5 ; 2 ; 5)}=\frac{5}{5}=1 \\
& \mathrm{R} 54=\frac{2}{\max (4 ; 4 ; 5 ; 2 ; 5)}=\frac{2}{5}=0,4 \\
& \mathrm{R} 55=\frac{5}{\max (4 ; 4 ; 5 ; 2 ; 5)}=\frac{5}{5}=1
\end{aligned}
$$

Untuk normalisasi 6 :

$$
\begin{aligned}
& \mathrm{R} 61=\frac{4}{\max (4 ; 4 ; 3 ; 3 ; 5)}=\frac{4}{5}=0,8 \\
& \mathrm{R} 62=\frac{4}{\max (4 ; 4 ; 3 ; 3 ; 5)}=\frac{4}{5}=0,8 \\
& \mathrm{R} 63=\frac{3}{\max (4 ; 4 ; 3 ; 3 ; 5)}=\frac{3}{5}=0,6 \\
& \mathrm{R} 64=\frac{3}{\max (4 ; 4 ; 3 ; 3 ; 5)}=\frac{3}{5}=0,6 \\
& \mathrm{R} 65=\frac{5}{\max (4 ; 4 ; 3 ; 3 ; 5)}=\frac{5}{5}=1
\end{aligned}
$$

Untuk normalisasi 7:

$$
\begin{aligned}
& \mathrm{R} 71=\frac{4}{\max (4 ; 2 ; 3 ; 3 ; 4)}=\frac{4}{4}=1 \\
& \mathrm{R} 72=\frac{2}{\max (4 ; 2 ; 3 ; 3 ; 4)}=\frac{2}{4}=0,5 \\
& \mathrm{R} 73=\frac{3}{\max (4 ; 2 ; 3 ; 3 ; 4)}=\frac{3}{4}=0,75 \\
& \mathrm{R} 74=\frac{3}{\max (4 ; 2 ; 3 ; 3 ; 4)}=\frac{3}{4}=0,75 \\
& \mathrm{R} 75=\frac{4}{\max (4 ; 2 ; 3 ; 3 ; 4)}=\frac{4}{4}=1
\end{aligned}
$$

Proses perhitungan normalisasi dilakukan hingga normalisasi ke 7 sehingga didapatkan hasil normalisasi seperti tertera pada Tabel 5.

Tabel 5. Hasil Normalisasi dengan Algoritma SAW

\begin{tabular}{cccccccc}
\hline Alternatif & \multicolumn{1}{l}{ K1 } & \multicolumn{1}{l}{ K2 } & \multicolumn{1}{l}{ K3 } & K4 & K5 & K6 & \multicolumn{1}{l}{ K7 } \\
\hline P1 & 1 & 1 & 1 & 0,8 & 0,8 & 0,8 & 1 \\
P2 & 1 & 1 & 1 & 0,6 & 0,8 & 0,8 & 0,5 \\
P3 & 0,8 & 0,75 & 0,75 & 0,8 & 1 & 0,6 & 0,75 \\
P4 & 0,8 & 0,75 & 1 & 1 & 0,4 & 0,6 & 0,75 \\
P5 & 0,8 & 0,75 & 0,5 & 0,8 & 1 & 1 & 1 \\
\hline
\end{tabular}

Setelah didapat hasil dari normalisasi, maka selanjutnya akan dibuat perkalian matriks (preferensi) untuk mendapatkan perangkingan dari semua alternatif.

Diketahui bobot nilai:

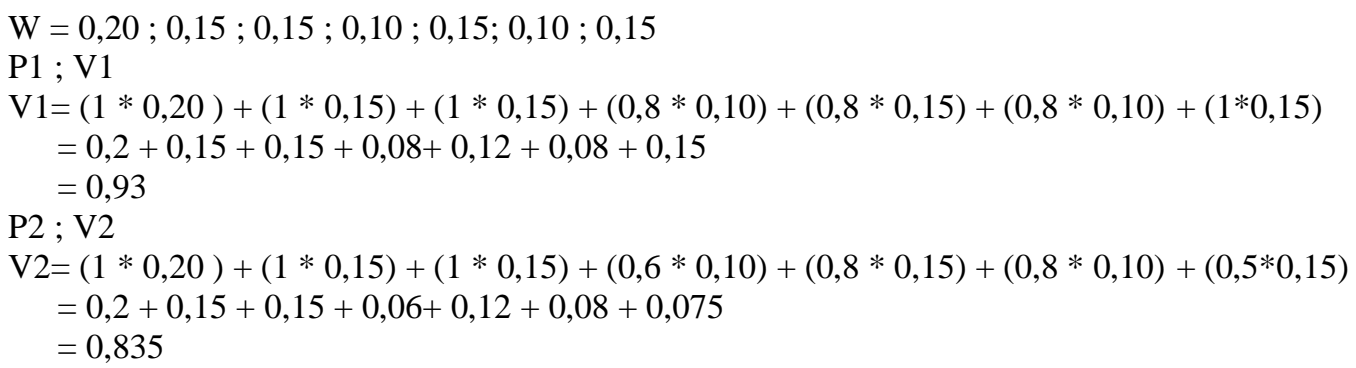




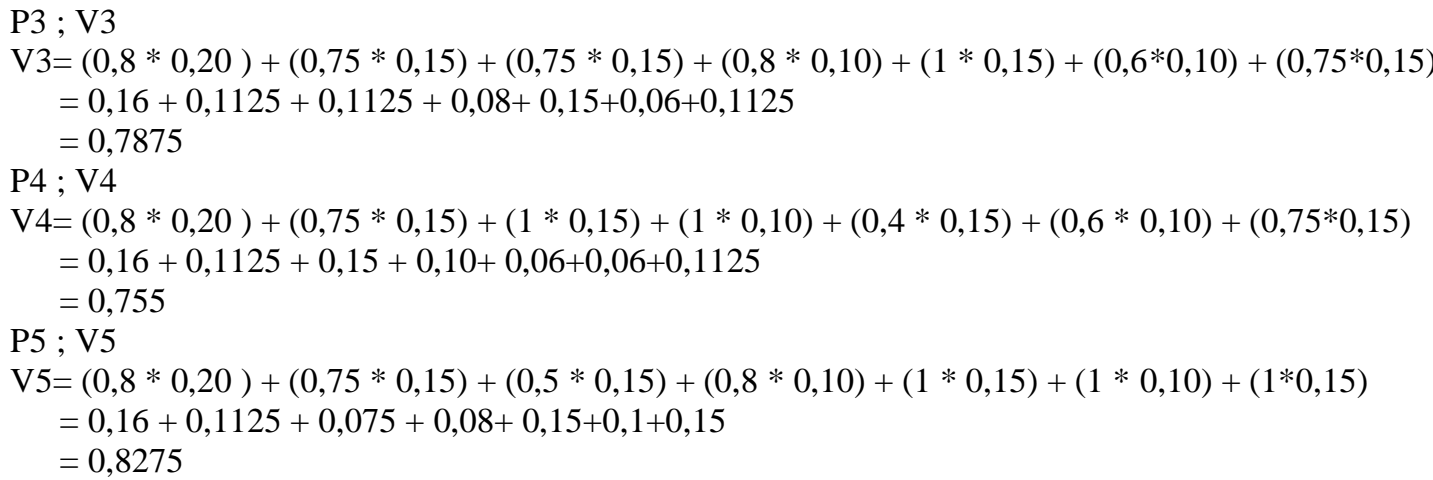

Proses perhitungan dan perkalian matriks $\mathrm{W} * \mathrm{R}$ dan penjumlahan hasil perkaliandilakukan hingga alternatif ke V5 sehingga didapatkan hasilnya seperti tertera pada Tabel 6

Tabel 6 Tabel Penjumlahan Hasil Perkalian W* R pada Algoritma SAW

\begin{tabular}{cc}
\hline Alternatif & $\mathrm{V}$ \\
\hline P1 & 0,93 \\
P2 & 0,835 \\
P3 & 0,7875 \\
P4 & 0,755 \\
P5 & 0,8275 \\
\hline
\end{tabular}

Dari tabel tersebut yang berupa hasil akhir perhitungan dan perkalian matriks, dapat disimpulkan bahwa yang memiliki nilai tertinggi adalah: Alternatif (P1) dengan nilai 0,93. Maka, P1 atas nama Rizal ditetapkan sebagai Pegawai yang terbaik di Dinas Pengelolaan Sumber Daya Air (PSDA) Unit Pelaksana Teknis Dinas (UPTD) 07 Tanah Jawa Kabupaten Simalungun berdasarkan perhitungan algoritma Simple Additive Weighting $(S A W)$

\section{IMPLEMENTASI}

Dalam implementasi sistem akan dibahas mengenai tampilan akhir antarmuka sistem yang disesuaikan dengan perancangan sistem yang telah dibuat sebelumnya.

\section{A. Tampilan Form Login.}

Tampilan ini muncul pada saat pertama sekali program dijalankan. Halaman ini menampilkan form login. Tampilan login dapat dilihat pada Gambar 1.

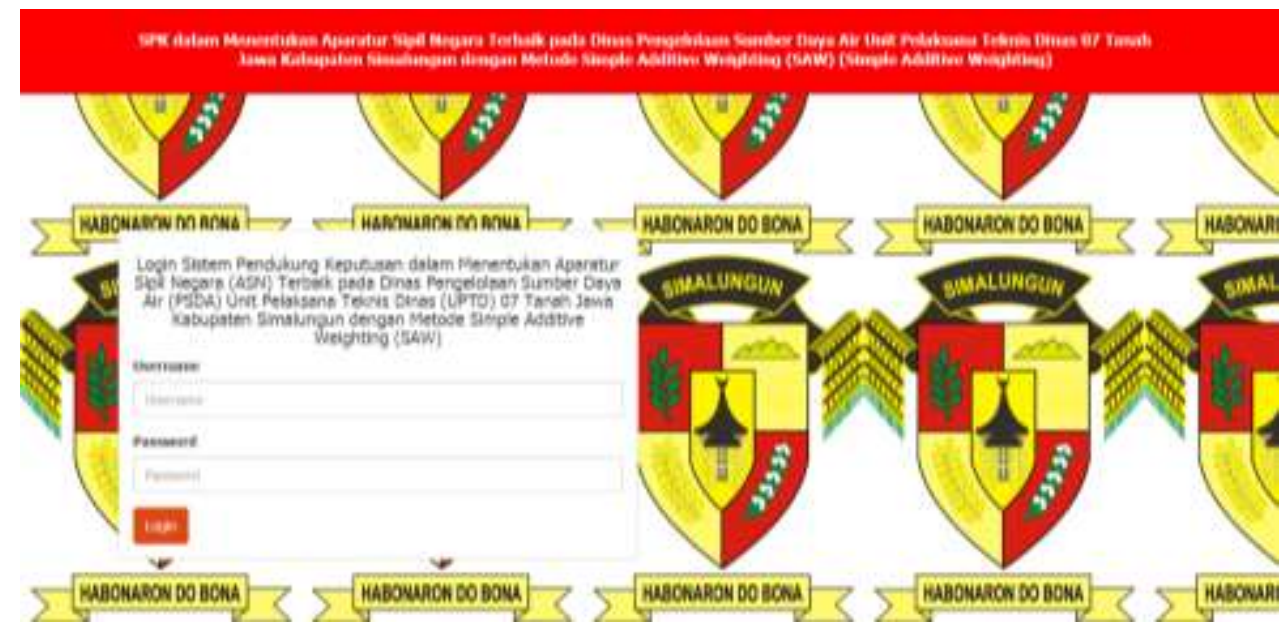

Gambar 1. Form Login

Untuk bisa menjalankan aplikasi, terlebih dahulu pengguna harus memasukkan username dan password kedalam sistem. username dan password harus sesuai dengan data yang ada didatabase sistem. Jika pengguna salah memasukkan username dan password, maka akan muncul pesan kesalahan error pada sistem. 


\section{B. Tampilan Form Utama}

Form ini menampilkan menu - menu yang ada pada form utama admin. Tampilan form ini dapat dilihat seperti pada Gambar 2 dibawah ini :

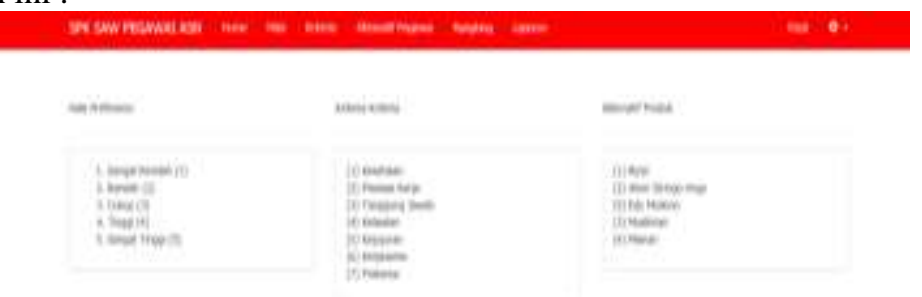

Gambar 2. Form Menu Utama

\section{Tampilan Form Nilai Preferensi}

Form ini ditujukan untuk menyimpan data Nilai Preferensi. Tampilan form Nilai Preferensi dapat dilihat seperti pada gambar 3 dibawah ini :

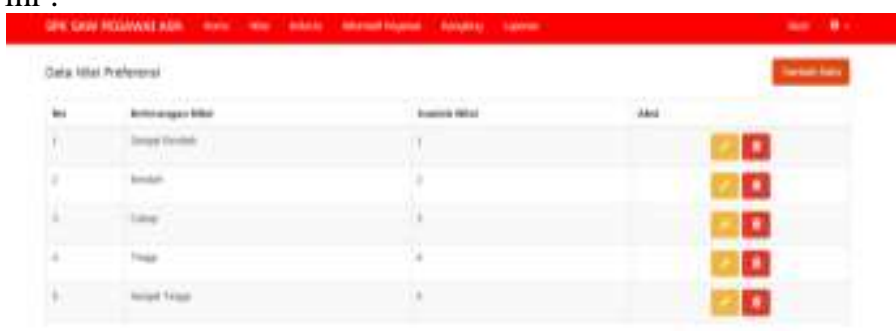

Gambar 3. Tampilan Form Nilai Preferensi

\section{Tampilan Form Data Kriteria}

Form ini ditujukan untuk menyimpan data kriteria. Tampilan form data kriteria dapat dilihat seperti pada gambar 4 dibawah ini :

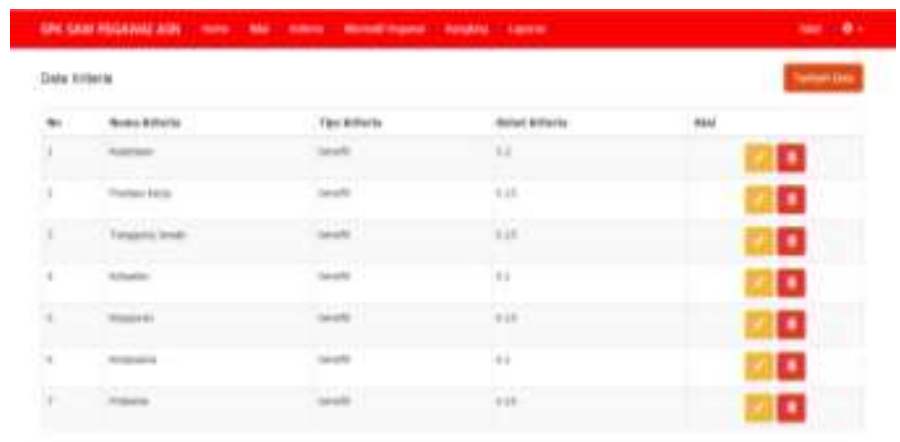

Gambar 4. Tampilan Form Kriteria

\section{E. Tampilan Alternatif}

Form ini ditujukan untuk menyimpan data Alternatif. Tampilan form data Alternatif dapat dilihat seperti pada gambar 5 berikut ini :

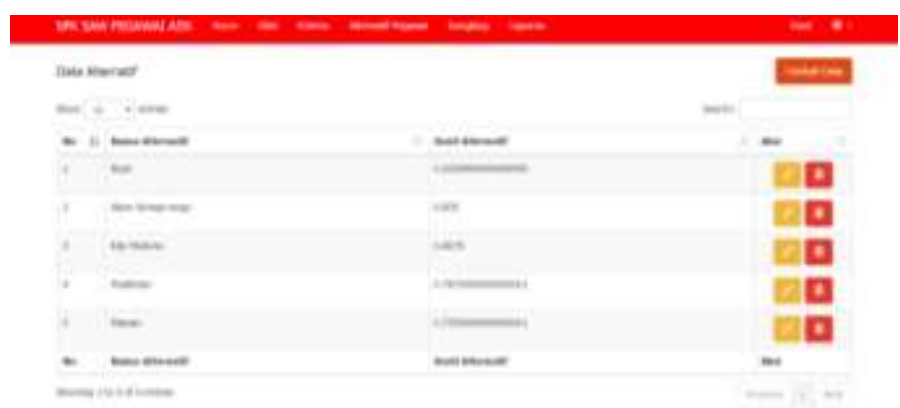

Gambar 5. Tampilan Form Alternatif 


\section{F. Tampilan Form Ranking}

Form ini ditujukan untuk menyimpan data Ranking. Tampilan form data Ranking dapat dilihat seperti pada gambar 6 dibawah ini :

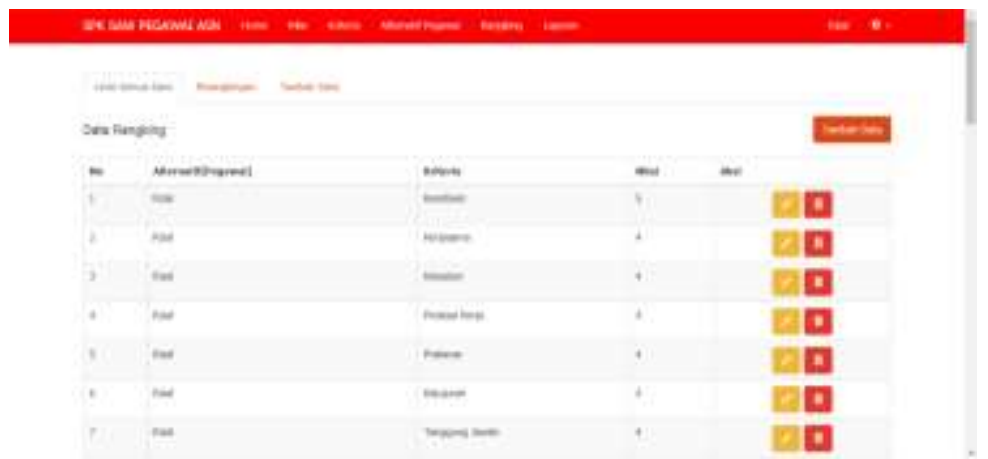

Gambar 6. Tampilan Form Ranking

\section{G. Tampilan Seleksi Alternatif}

Tampilan form ini menampilkan hasil keseluruhan dari proses Simple Additive Weighting (SAW). Pada form ini tidak ada proses penginputan data. Proses ini akan melakukan perhitungan otomatis sesuai dengan nilai kriteria dan bobot yang dimasukkan oleh pengguna. Form ini menampilkan beberapa perhitungan otomatis seperti perhitungan nilai normalisasi, nilai normalisasi terbobot dan nilai preferensi (skor terakhir). Sebelum melakukan proses perhitungan, pengguna akan disajikan pilihan data periode pencetakan sebelum melakukan pencetakan dan proses perhitungan data. Tampilan form seleksi alternatif dapat dilihat pada gambar 7 dan 8 berikut:

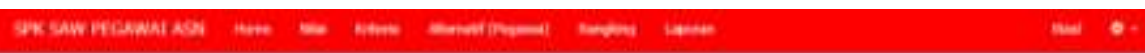

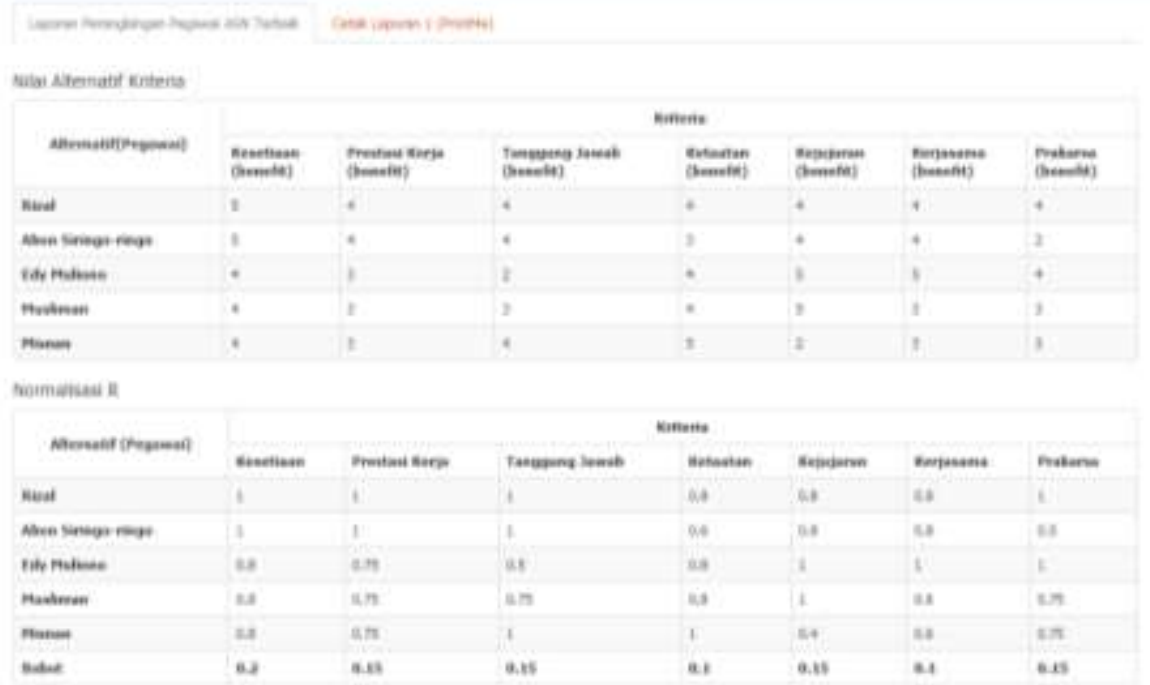

Gambar 7. Tampilan Form Seleksi Alternatif untuk Nilai Awal
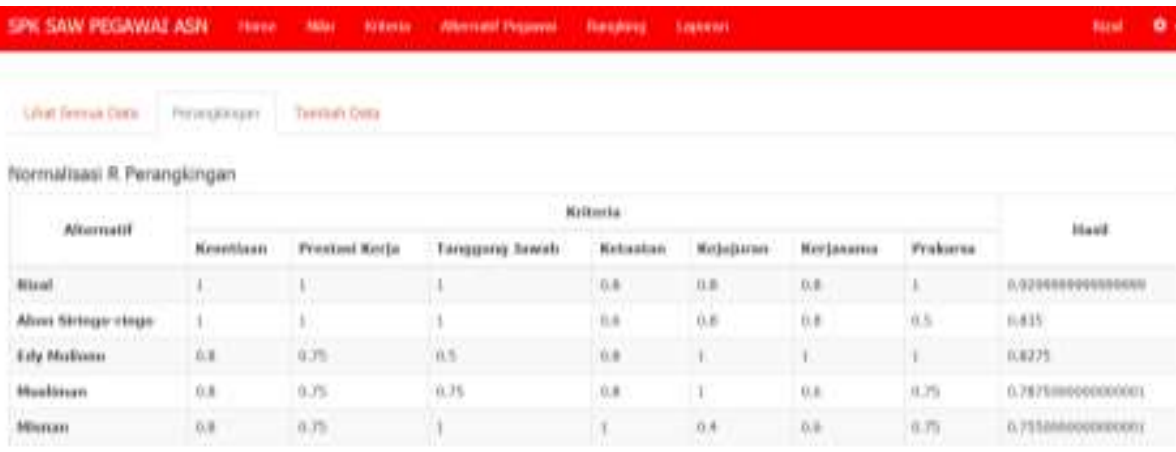

Gambar 8 Tampilan Form Seleksi Alternatif untuk Nilai Normalisasi 


\section{H. Hasil Penilaian Sistem}

Dari hasil perhitungan yang dilakukan oleh sistem, didapat pada gambar 9 dibawah ini:

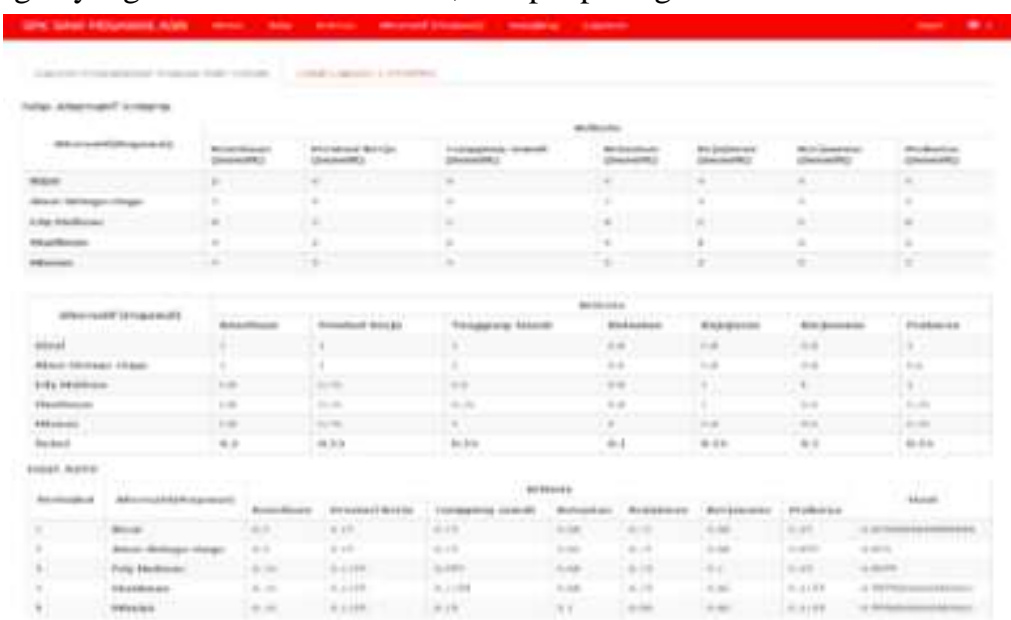

Gambar 9. Tampilan Hasil Penilaian Sistem

\section{KESIMPULAN}

Sistem Pendukung Keputusan dalam Menentukan Aparatur Sipil Negara (ASN) Terbaik pada Dinas Pengelolaan Sumber Daya Air (PSDA) Unit Pelaksana Teknis Dinas (UPTD) 07 Tanah Jawa Kabupaten Simalungun dengan Metode Simple Additive Weighting $(S A W)$ yang telah diselesaikan ini, dapat diambil beberapa kesimpulan antara lain :

1. Proses Pengambilan Keputusan dalam Menentukan Aparatur Sipil Negara (ASN) Terbaik pada Dinas Pengelolaan Sumber Daya Air (PSDA) Unit Pelaksana Teknis Dinas (UPTD) 07 Tanah Jawa Kabupaten Simalungun Dengan Metode Simple Additive Weighting (SAW) meliputi beberapa kriteria yaitu kesetiaan, prestasi kerja, tanggung jawab, ketaatan, kejujuran, kerjasama dan prakasa.

2. Sistem ini bertujuan untuk membantu dalam melakukan penilaian kinerja, melihat kinerja Pegawai terbaik dan laporan Pegawai yang memiliki kinerja terbaik.

3. Perhitungan pada sistem untuk melakukan penyeleksian menggunakan metode SAW (Simple Additive Weighting).

4. Tahap - tahap proses pengembangan sistem dalam penelitian ini adalah identifikasi masalah, analisis sistem, perancangan, pengujian dan implementasi.

5. Hasil dari perhitungan sistem merupakan perangkingan nilai tertinggi ke rendah dan nilai tertinggi merupakan hasil untuk memperoleh Pegawai yang memiliki kinerja terbaik.

6. Sistem yang dibangun hanya sebagai alat bantu untuk memberikan informasi kepada pimpinan sebagai bahan pertimbangan dalam mengambil keputusan.

\section{REFERENCES}

[1] Bentley, Lonnie D dan Whitten, Jeffrey L. 2007. Systems Analysis and Design for the Global Enterprise, $7^{\text {th }}$ Edition, International Edition. McGrawHill, New York.

[2] Davis, Ralp C dalam Hasan. (2004). Pokok-pokok Materi Teori Pengambilan Keputusan. Jakarta: Ghalia Indonesia.

[3] Ladjamuddin, Al-Bahra. 2006. Analisis dan Desain Sistem Informasi. Yogyakarta : Graha Ilmu.

[4] Turban, Efraim, Jay E. Aronson dan Ting-Peng Liam. 2005. Decision Support Systems and Intelligent Systems. Yogyakarta : Penerbit Andi.

[5] Umar, Daihani dan Dadan. 2001. Komputerisasi Pengambilan Keputusan. PT Elex Media Komputindo : Jakarta

[6] Undang-Undang Nomor 5 Tahun 2014 tentang Aparatur Sipil Negara

[7] S. H. Sahir, R. Rosmawati, and K. Minan, "Simple Additive Weighting Method to Determining Employee Salary Increase Rate," Int. J. Sci. Res. Sci. Technol., vol. 3, no. 8, pp. 42-48, 2017.

[8] D. C. Hartini, E. L. Ruskan, and A. Ibrahim, "Sistem Pendukung Keputusan Pemilihan Hotel Di Kota Palembang Dengan Metode Simple Additive Weighting (SAW)," J. Sist. Inf., vol. 5, no. 1, pp. 546-565, 2013.

[9] R. T. Utami, D. Andreswari, and Y. Setiawan, "Implementasi Metode Simple Additive Weighting (SAW) dengan pembobotan Rank Order Centroid(ROC) Dalam Pengambilan Keputusan Untuk Seleksu Jasa Leasing Mobil," $J$. Rekursif, vol. 4, no. 2, pp. 209-221, 2016.

[10] Khairul;, M. Simaremare, A. Putera, and U. Siahaan, "Decision Support System in Selecting The Appropriate Laptop Using Simple Additive Weighting," Int. J. Recent TRENDS Eng. Res., vol. 2, no. 12, pp. 215-222, 2016. 